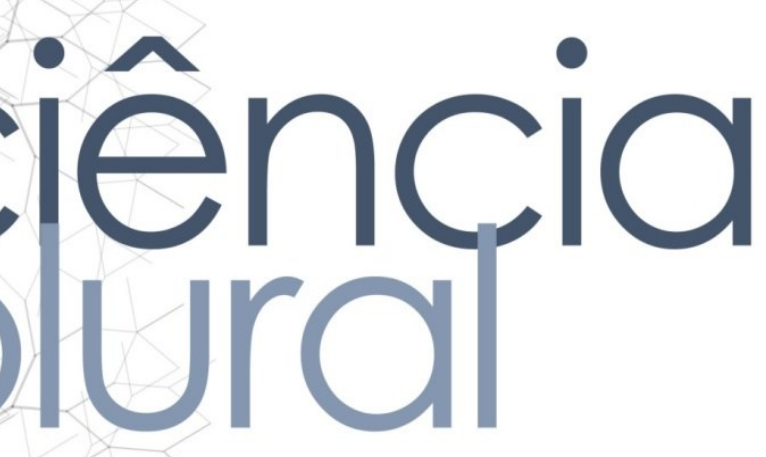

\title{
DISCRIMINAÇÃO VIVENCIADA POR PESSOAS QUE VIVEM COM HIVIAIDS NOS SERVIÇOS DE SAÚDE: UM ESTUDO QUALITATIVO
}

\section{Discrimination experienced by people living with HIV / AIDS in health services: a qualitative study}

Ricardo Takeda Lelis - Mestre do Programa de Odontologia Preventiva e Social, Faculdade de Odontologia, UNESP Univ. Estadual Paulista, 14801-903 Araçatuba - SP, Brasil. E-mail: takeda@bol.com.br

Gabriella Barreto Soares - Doutora do Programa de Odontologia Preventiva e Social, Faculdade de Odontologia, UNESP Univ. Estadual Paulista, 14801-903 Araçatuba - SP, Brasil. E-mail: gabriella.barreto@yahoo.com.br

Artênio José Ísper Garbin - Professor Adjunto do Programa de Odontologia Preventiva e Social, Faculdade de Odontologia, UNESP Univ. Estadual Paulista, 14801-903 Araçatuba - SP, Brasil. E-mail: argarbin@foa.unesp.br

Cléa Adas Saliba Garbin - Professora Titular do Programa de Odontologia Preventiva e Social, Faculdade de Odontologia, UNESP Univ. Estadual Paulista, 14801-903 Araçatuba - SP, Brasil. E-mail: cagarbin@foa.unesp.br

Autor responsável pela correspondência:

Gabriella Barreto Soares. Rua Gonçalves Dias 165. Laranjeiras Serra, ES, Brasil. Tel: +55 (27)981000511. E-mail: gabriella.barreto@yahoo.com.br 


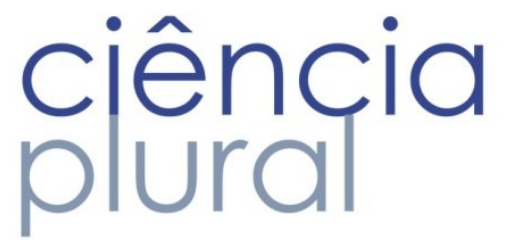

\section{RESUMO}

Introdução: Já se passaram mais de três décadas desde a descoberta da AIDS, e as pessoas que vivem com HIV ainda são estigmatizadas não só pela sociedade, como também nos serviços assistenciais de saúde. Objetivos: Diante disso, o objetivo deste estudo é analisar as situações discriminatórias na assistência a saúde de pessoas com HIVIAIDS. Materiais e Métodos: Foram realizadas entrevistas semiestruturadas, após o consentimento livre e esclarecido, com 19 pessoas que vivem com HIVIAIDS assistidas por ONGs/AIDS de quatro municípios brasileiros, e que afirmaram previamente já terem sofrido algum tipo de discriminação por profissionais de saúde. As entrevistas foram gravadas e posteriormente transcritas e analisadas utilizando-se a análise de conteúdo. Resultados: As atitudes discriminatórias ocorreram por meio do atendimento diferenciado, recusa de tratamento ou pela utilização de medidas extras de biossegurança, tendo ocorrido inclusive em instituições de ensino superior na área da saúde. Conclusão: É necessária a adoção de estratégias para combater a ocorrência de tais atos objetivando-se a humanização na assistência a saúde de pessoas com HIVIAIDS e a melhoria na qualidade de vida desses pacientes.

Palavras Chave: HIV; Discriminação social; Pessoal de saúde.

\section{ABSTRACT}

Introduction: Three decades will have passed since the discovery of AIDS, and the people living with HIVIAIDS still were estigmatizated not only in the society, as well as in health care services. Objective: It aimed to analyze the discriminatory situations in the assistance to the health of HIV-positive individuals. Methods: It was carried out face to face semi-structuralized interviews with nineteen people living with HIVIAIDS who had been discriminated by health care workers. These people were attended by Not Governmental Organizations for AIDS (NGO/AIDS) from four Brazilian cities. The interviews were recorded and then transcribed and analyzed through the content analysis. Results: The discriminatory attitudes occurred through the differentiated attendance, refusal of treatment or by the adoption of extra precautions measures, having also occurred in colleges with courses in health area. Conclusions: The adoption of strategies to fight against the occurrence of such acts is necessary aiming at human assistance to the health of HIV-positive patients and the improvement in the life quality of these patients.

Keywords: HIV; Social discrimination; Health personnel 


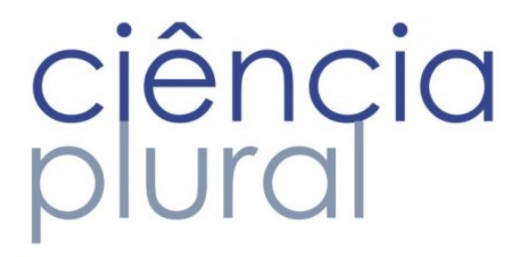

\section{Introdução}

A epidemia de HIVIAIDS entra em sua quarta década, com características epidemiológicas e clínicas diferentes daquelas observadas no seu surgimento. Isto acontece devido aos avanços no diagnóstico e tratamento, com destaque na introdução da terapia antirretroviral (TARV) mais efetiva que levou ao aumento da expectativa de vida das pessoas que vivem com a doença ${ }^{1,2}$. Contudo, mesmo passado tantos anos, muitas dessas pessoas ainda sofrem discriminação, não só por parte da sociedade, mas também por profissionais de saúde.

No início da epidemia, associavam-se às PVHA aos homossexuais, usuários de drogas injetáveis e aos profissionais do sexo, sendo chamada popularmente de "peste gay" ou "câncer gay", que junto ao medo de contágio da população trouxe como consequência um reforço ao preconceito e a discriminação contra essa parte da população ${ }^{3}$.

Outro fator também responsável pela estigmatização das pessoas com HIV/AIDS foi a forma como a mídia abordou a epidemia em seu início. Em 1981, antes mesmo do registro do primeiro caso da doença no país, a imprensa brasileira divulgava as primeiras matérias sobre o "câncer gay"4. Nesse mesmo momento, a mídia introduziu noções discriminatórias na sociedade, como a existência de grupos de risco (constituídos pelos transgressores, pecadores, promíscuos e imorais) fortemente presentes no imaginário social no início da epidemia, deixando até hoje impressões difíceis de serem removidas 5 .

A dificuldade em se abordar a epidemia da AIDS reside no fato de ela envolver três componentes extremamente complexos: o sexo, ao qual a AIDS estaria relacionada de maneira muito direta; a moral, que é consequência de a doença estar relacionada à sexualidade, ao comportamento sexual de cada um; e a morte, o medo de morrer. 0 fato de a doença estar relacionada à questão do sexo e do homossexualismo revelaria dois lados perversos: a repressão sexual e o moralismo, os quais levam "a dois subprodutos extremamente complicados e danosos a qualquer sociedade humana, que é a criminalização de um fenômeno e a marginalização das pessoas que são afetadas por uma doença", onde a preocupação excessiva sobre os comportamentos humanos ocasionaria 0 afastamento do entendimento e tratamento da doença em sí.

A discriminação na assistência à saúde de pessoas com HIVIAIDS pode ocorrer pela recusa de atendimento, pelo tratamento diferencial a esses pacientes, por meio da revelação da condição sorológica para outras pessoas, pela isolação física dos mesmos não justificada biologicamente e através do 


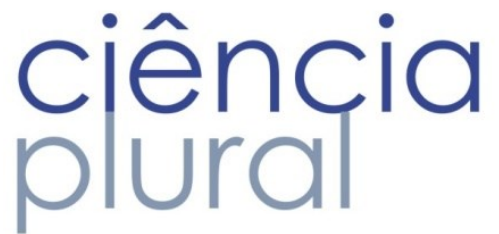

aconselhamento de intervenções que não seriam indicadas a outros pacientes, como 0 aborto e a esterilização ${ }^{7-9}$. Há ainda a adoção de medidas diferenciadas de biossegurança, uma forma de discriminação bastante peculiar e praticada por muitos profissionais de saúde ${ }^{10,11 .}$

Muitos são os trabalhos que apontam comportamentos e atitudes discriminatórias de profissionais de saúde com relação ao atendimento de pessoas que vivem com HIVIAIDS ${ }^{12-15}$. No entanto, raros são os estudos que buscam o entendimento desse tema a partir da visão dos próprios portadores. Dessa forma, fazse necessário analisar as atitudes discriminatórias de profissionais de saúde com relação a pacientes HIV soropositivos, identificando e compreendendo a maneira como estas ocorrem a partir da percepção dos próprios pacientes, para que assim, sejam gerados dados que possam subsidiar a elaboração de estratégias eficazes para o seu controle.

\section{Material e Métodos}

O estudo foi de natureza qualitativa, no sentido de buscar significados, opiniões, sentimentos, como possibilidade de entender (analisar) o fenômeno social e suas relações à intimidade de cada pessoa com HIVIAIDS16.

A pesquisa foi realizada nas Organizações Não Governamentais de assistência a pessoas com HIVIAIDS (ONG/AIDS) das cidades de Araçatuba-SP, Birigui-SP, Uberlândia-MG e Dourados-MS, pois assim haveria maior facilidade em encontrá-los, e também porque a abordagem aos mesmos nas próprias Unidades Básicas de Saúde poderia causar a inexatidão ou a omissão de dados e uma maior recusa de participação na pesquisa devido ao receio de sofrerem retaliações.

A amostra da presente pesquisa foi constituída por 19 pessoas com HIVIAIDS que afirmaram previamente ter sofrido discriminação por profissionais de saúde e que consentiram em participar da pesquisa.

Para a coleta dos dados optou-se pela realização de entrevistas semi-estruturadas individuais, norteadas por um roteiro que abordava questões relacionadas a discriminação vivenciada nos serviços de saúde. As entrevistas foram gravadas utilizando-se um aparelho gravador de áudio Panasonic modelo RN202, para que os relatos fossem posteriormente transcritos e analisados.

Para a análise dos dados coletados, foi utilizada a análise de conteúdo, a qual se presta ao estudo das motivações, atitudes, valores e crenças, contidas nas mensagens. 


\section{ciência plural}

\section{Resultados}

Foram identificadas 28 pessoas que afirmaram ter sofrido discriminação por profissionais de saúde, dentre as quais, 9 não aceitaram ser entrevistadas. Assim, foram entrevistadas 19 pessoas, sendo que 12 haviam vivenciado uma situação discriminatória, 4 haviam sido discriminadas duas vezes, 1 foi discriminada três vezes e 2 vivenciaram quatro situações de discriminação na área da saúde. Dessa forma, foram totalizados 31 relatos de situações de discriminação praticadas por profissionais de saúde.

Aplicando-se a análise temática aos conteúdos dos relatos obtidos, foram determinadas três unidades de registro, segundo as quais os relatos foram categorizados em: a recusa de atendimento, 0 atendimento diferenciado e a adoção de medidas extras de biossegurança.

\section{A recusa de atendimento como forma de discriminação.}

Dentre as 31 situações de discriminação relatadas pelas pessoas entrevistadas, 12 foram referentes a esta categoria. Houve situações em que 0 tratamento foi interrompido a partir do momento em que 0 paciente revela a sua soropositividade para HIV. Nos relatos, algumas pessoas indignam-se pela possibilidade de o profissional atender outros portadores do HIV sem ter conhecimento disso.

"(...) aí, comę̧ou a me dar dor de dente, aí eu fui procurar um dentista, aí eu cheguei num posto lá perto da casa de recuperação que tinha, ai o homem [cirurgião-dentista] tava tratando tudo certinho dos meus dentes, aí, na hora que ele foi mexer com, mexer com negócio de sangue, que ele ia arrancar com o buticão, que ele ia ponhá pra arrancar com o buticão, aí eu falei pra ele que eu tinha, que eu era soropositivo. Eu falei: só que eu sou soropositivo. - Aí, ele tirou a mão na hora, soltou o alicate assim [faz movimento de susto]. E ele falou: Então você não pode ser atendido aqui não, você tem que ir em outro lugar [...]. E as pessoas que vão lá, que não revelam que é um soropositivo? Trata sem saber. E é até mais perigoso. Agora eu pelo menos fui realista e falei pra ele, né. $E$ o outro que tem e nem fala nada. Ele trata, nem sabe e passa batido. Não é verdade?" (D.A.L.A., 29, situação ocorrida há seis anos).

Em outras situações 0 atendimento é recusado tendo como justificativa a falta de horário devido ao grande número de pacientes em tratamento (em uma clínica particular). Segundo o relato a seguir, a pessoa discriminada, apesar da situação vivenciada, ressalta a sua atitude de sempre revelar sua condição sorológica, mesmo tendo que sofrer as "consequências" de tal ato.

"Que nem uma dentista aqui perto, eu fui lá e falei minha situação, revelei minha situação, né $[H I V+]$, eu revelo pra qualquer um, onde eu for, pode ser público, particular, eu revelo sim, mas depois vêm as consequências, né. Aí, ela disse que eu tinha que pegar um atestado com o médico, tal (...), eu fui, busquei, levei [o atestado], levei pra ela, aí 


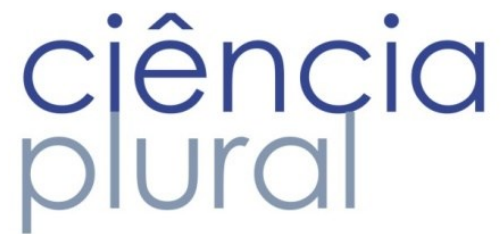

ela disse que não, que ela tinha muitos pacientes, mas eu logo deduzi que a causa foi essa [ser HIV+], mas a gente tem que revelar, tem que revelar, mas sofre, né". (MCALA, 42 anos, situação ocorrida há 9 anos).

Em alguns relatos 0 atendimento é recusado até que por algum motivo o profissional vê- se "obrigado" a atender o paciente.

“...) quando eu cortei o braço, que tava sangrando muito, cortou um vasinho, eu fui até o pronto socorro, eu peguei e falei pra enfermeira que eu tinha plaqueta baixa e não podia ficar sangrando, e ela pegou e perguntou pra mim: - Ué, mas como você sabe que tem plaqueta baixa? E eu peguei e falei pra ela: - Porque eu sou portador do vírus [HIV] e a proteção baixa e não estanca. E tava sangrando muito, eu já tava ficando até meio tonto, meio pálido. E o médico não queria mexer, se minha mãe não fala de chamar a polícia, ele não queria costurar meu braço e um ficava jogando pro outro, disse que tinha mudado o plantão, que um tinha passado pro outro, e não sei o que, e eu sangrando, enquanto minha mãe não chegou lá e falou que ou ele mexia ou minha mãe ia chamar a polícia, ele não costurou". (ASSB, 31 anos, situação ocorrida há 4 anos).

Em outras situações o profissional de saúde se quer fornece alguma justificativa para tal atitude, limitando-se simplesmente a se "esconder" do paciente, o que revela uma total falta de consideração e respeito à pessoa portadora do HIV.

"Eu deduzo assim que foi uma discriminação, porque eu preciso usar aparelho, né. E logo de imediato eu entrei em contato com esse dentista, ele tirou um molde certinho da boca pra colocar o aparelho e ele mandou eu voltar depois de uma semana (...), falei com a secretária, e a secretária toda vez que procurava ele, dizia que ele não tava, e eu ficava na porta esperando, e eu via que ele tava lá dentro, e tava atendendo o pessoal. Então, é, é, eu achei que foi um ato assim de discriminação, porque ele ficou sabendo que eu era soropositivo e ele não quis me atender. No entanto, quando eu entrei, que não coloquei a situação [ser HIV+], ele me atendeu numa boa, depois que eu falei pra ele que eu era soropositivo (...) ele continuou me atendendo, só que ao voltar lá, o atendimento já não foi igual ao do primeiro dia. Acho que ele ouviu tudo o que ele tinha que ouvir pra poder disfarçar mais pra frente e me dispensar, você entendeu?". (RCS, 31 anos, situação ocorrida há 2 anos e meio).

Foi relatada outra situação em que o profissional de saúde recusou-se a continuar o tratamento do paciente HIV positivo, justificando tal decisão devido a reclamações de outros pacientes, ao ficarem sabendo que o mesmo também prestava atendimento a portadores do HIV.

“(...) e esse camarada é um dentista da rede pública (...) e ele começou a tratar dos meus dentes tal, aí, um belo dia ele chegou e falou pra mim: $R$. eu não quero tratar mais de você porque é o seguinte, algumas pessoas já vieram me falar aqui que você é portador e eles não querem vim tratar mais (...) então foi um choque, né. Um negócio esquisito, 


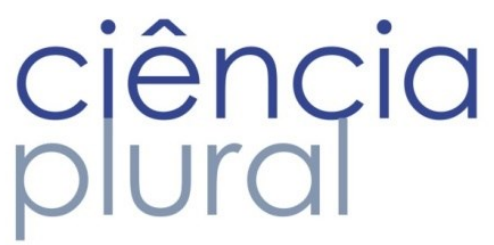

você se sente assim, o chão meio treme, né, aquela coisa, pô, mas por quê? O atendimento não é o mesmo pra cada um? O fato é que eu me senti muito mal naquela época". (RJLQ, 49 anos, situação ocorrida há 3 anos).

Houve ainda, situações de discriminação em Faculdades de Odontologia, onde, potencialmente, este problema poderia ser combatido. Justificou-se a recusa do atendimento alegando-se a falta de condições técnicas e estruturais, tais alegações, muitas vezes estapafúrdias, beiram o desrespeito não só à pessoa, como à sua capacidade inteligível.

“(...) teve uma vez também que eu fui lá [uma Faculdade de Odontologia], e eles alegaram pra mim que, a partir do momento que eu tinha isso aí [AIDS], eles alegaram pra mim que eles não podiam mexer comigo ali, porque ali não existia esterilização suficiente. Aí então, até eu perguntei assim pra ele, falei assim: mas ué, então eu corro o risco tanto de passar para uma outra pessoa, quanto de adquirir isso - Aí, foram lá, entraram num conselho lá, conversaram lá, aí eles falaram pra mim que iam arrumar pessoas capacitadas para fazer meu tratamento, e, retornaria a me chamar, isso até hoje, não me chamaram mais, isso já faz uns dois anos, um ano e meio mais ou menos". (A.S.S.B., 31 anos, situação ocorrida há dois anos).

\section{0 atendimento diferenciado como forma de discriminação.}

Das 31 situações discriminatórias relatadas pelas pessoas entrevistadas, 16 foram referentes a esta categoria. Em certas situações de atendimento diferenciado, há relatos em que o profissional atende 0 paciente HIV positivo de forma grosseira e se considerarmos o contexto, de forma desumana, como na situação descrita a seguir, onde a pessoa relata uma situação ocorrida quando sua esposa, também portadora, estava grávida do primeiro filho do casal.

"Então dessa parte eu acho que eu fui discriminado por causa das palavras dele. Ele sempre foi grosso, sempre foi grosso, nunca foi hospitaleiro, nunca, nunca, nunca, sempre com estupidez, todo atendimento dele era bruto. Ele falou de forma grosseira: - Do jeito que você ta aí, você nem vai ver seu filho nascer. Aí, passou o tempo, encontrei com ele, e tive o prazer de falar que, que vi meu filho nascer sim". (PSFC, 33 anos, situação ocorrida há 6 anos).

De outro modo, deixar o atendimento de pessoas com HIVIAIDS para o último horário do período, seria outro tipo de atendimento diferenciado a que essas pessoas são submetidas.

"Eu cheguei e fui fazer o ultrassom. Ai eu entreguei o papel pra ela (onde constava ser HIV+). Aí ela pegou, escreveu lá meu nome, mandou eu assinar, aí eu falei pra ela: - Que número eu sou? E ela falou: - A quarta (...). Aí o médico chegou quinze pras oito, aí foi entrando as pessoas que estavam lá, entrou a primeira, depois entrou a segunda, entrou a terceira. Aí eu falei pra minha irmã: - Bom, já que entrou a terceira, eu vou ser a quarta, né(...) aí ela (a 


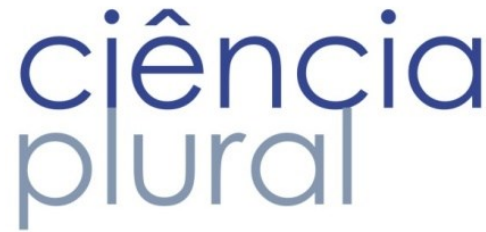

enfermeira) pegou saiu lá e falou assim pra mim: - Oh, Dona J. eu vou passar essa mulher aqui na sua frente porque ela ta com um probleminha. Mas eu pensei, porque era uma pessoa de idade, falei tudo bem. Aí, passou aquela, depois passou a outra, passou a outra (...), aí passou tudo, eu fui a última, porque eram dez pessoas, fui a número dez". (JES, 53 anos, situação ocorrida há 1 ano e meio).

Em certas situações, um atendimento diferenciado, grosseiro, pode ter consequências comprometedoras para o estado de saúde das pessoas com HIVIAIDS, que já estão abaladas emocionalmente por ter a doença.

"Eu fiquei um bom tempo sem ir no médico, por causa que o médico um dia falou alto comigo. Bateu na mesa e falou alto comigo, porque eu precisei de um atestado dele pra levar no INSS. E aí, a partir daquele momento, fiquei lá no canto chorando, chorando, falei pro meu marido, nunca mais enquanto este médico estiver aqui, eu não vou voltar mais aqui. Aí, eu não fui mais no médico, com isso fui me sentindo pior, os exames eu não fiz mais (...) (EC, 35 anos, situação ocorrida há 1 ano).

\section{A adoção de medidas extras de biossegurança como forma de discriminação.}

Dentre as 31 situações de discriminação relatadas pelas pessoas entrevistadas, 3 foram referentes a este tipo de categoria. No relato a seguir, o atendimento ao portador de HIV foi evitado ao máximo até 0 momento em que o profissional realizou o procedimento utilizando vários pares de luvas.

"Quando a minha mãe chegou, falou que ele ia mexer ou chamar a polícia, ai ele até colocou três ou quatro luvas na mão, entendeu? Costurou que nem costura porco, mas, mas costurou". (ASSB, 31 anos, situação ocorrida há 4 anos).

Em outra situação, houve relatos referentes à adoção de medidas extras de biossegurança (no caso a utilização de mais pares de luvas) que, quando percebidas pelos portadores do HIV, ocasionaria certa agressão emocional em pessoas já abaladas psicologicamente.

“(...) ela não me tratou mal não, ela só ficou com os olhos arregalados e, e colocou três luvas. Então, é como eu te falei, se fosse alguém que não tivesse um preparo psicológico quanto à doença que tem, ficaria até chateado, né. Isso daí psicologicamente afeta quem não ta preparado, né. Pôxa ela colocou três luvas, é um negócio chato". (MMM, 37 anos, situação ocorrida há 3 anos).

\section{Discussão}

Dentre as formas de discriminação relatadas pelas pessoas com HIVIAIDS, a de maior ocorrência foi 0 atendimento diferenciado por profissionais de saúde. As situações narradas demonstram um atendimento 


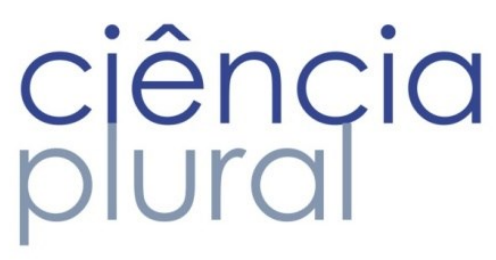

desrespeitoso, desumano e diferente do que seria feito com outros pacientes. Em estudo realizado por Schuster et al ${ }^{17}$, foi observado que esse tipo de discriminação foi também o de maior prevalência, onde as pessoas que vivem com HIV haviam sido atendidos de forma desconfortável e tratados com inferioridade.

Esse atendimento diferenciado é de difícil compreensão, pois para tanto teríamos que encontrar os motivos de tais profissionais para adotarem essas atitudes. Não podemos esquecer que os profissionais de saúde, essencialmente, são produtos da sociedade, e, de modo geral, adquirem dela, durante a sua formação, suas crenças e seus valores, podendo dessa forma, herdar as ideias estigmatizantes com relação as pessoas que vivem com HIV18,19.

A ocorrência de recusa de atendimento relatada pelas pessoas HIV soropositivo esteve relacionada diretamente às suas condições sorológicas, tendo ocorrido inclusive a interrupção do tratamento logo após os pacientes revelarem sua soropositividade para o HIV aos profissionais de saúde.

Panebianco et al ${ }^{20}$ ao analisarem as queixas de violações de direitos humanos junto ao CONASIDA (Centro Nacional para la Prevención y el Control del VIH/SIDA - México), verificaram que a maioria das reclamações era devido à recusa de atendimento (41\%). Por meio dos relatos foi possível observar que a grande maioria das situações discriminatórias representadas pela recusa de atendimento foi atribuída aos cirurgiões-dentistas, cujas atividades apresentavam maior risco de contaminação por estarem mais expostas ao sangue. Diferentemente dos médicos, onde se observou, através dos relatos, que suas atividades estavam relacionadas, quase em sua totalidade, a consultas clínicas, portanto, não expostos ao sangue do paciente. Esse fato talvez explique a maior ocorrência de discriminação devido a atendimentos diferenciados envolvendo esses profissionais e a recusa de atendimento envolvendo aqueles profissionais ${ }^{20}$.

Vale ressaltar que esse tipo de discriminação pode ser percebido de forma equivocada, como no caso de encaminhamento para centros mais preparados para o atendimento de portadores do HIV ser entendido como recusa de atendimento ${ }^{19}$. Analisando os relatos, esse tipo de falsa discriminação ocorreu uma única vez na amostra estudada, onde a paciente, ao procurar atendimento em uma unidade de saúde quando a epidemia estava no início, foi encaminhada para um centro de saúde que estaria mais bem preparado para o seu tratamento.

A alta carga preconceituosa existente na sociedade civil em relação a portadores do HIV é bem conhecida. O receio de perder outros pacientes por ficarem sabendo que determinado profissional de saúde atende também portadores do HIV é uma das justificativas para estes profissionais recusarem pessoas com 


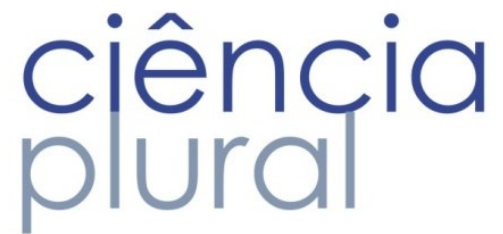

HIVIAIDS ${ }^{21}$. Essa situação foi relatada por uma pessoa nesse estudo, embora 0 atendimento estivesse sendo realizado no serviço público de saúde.

Segundo estudo de Giuliani et al22, o receio de ter 0 tratamento recusado ou um atendimento diferenciado, juntamente com o medo de outras pessoas ficarem sabendo de sua soropositividade para 0 HIV, levaram os pacientes com HIVIAIDS a não revelarem a sua condição sorológica para seus cirurgiõesdentistas ${ }^{23}$. Esse fato é preocupante, pois pode trazer consequências prejudiciais ao paciente durante 0 seu tratamento. Ao mesmo tempo expõe a importância da adoção de medidas universais de biossegurança por profissionais de saúde no atendimento de todos os pacientes. É ainda preocupante, uma vez que alguns profissionais de saúde são negligentes quanto à isso22.

Outra forma de discriminação relatada pelas pessoas com HIVIAIDS foi a adoção de medidas extras de biossegurança ao serem atendidas. Alguns trabalhos envolvendo profissionais de saúde comprovam essa atitude quando o paciente a ser atendido é portador do HIV ou é pertencente a algum "grupo de risco"18,19. A adoção de medidas extras de biossegurança ocorreu por meio da utilização de mais pares de luvas durante 0 atendimento. Essa atitude seria dispensável considerando-se 0 baixo potencial de transmissibilidade ocupacional do HIV, onde medidas universais de biossegurança adotadas corretamente são suficientes para a sua prevenção.

A percepção de atitudes discriminatórias praticadas por profissionais de saúde pode desestimular os pacientes HIV soropositivo a continuar o tratamento, aderir a programas de tratamentos ou a retornar às consultas ${ }^{24}$. Esse fato foi comprovado por relato de uma paciente nesse estudo, que interrompeu 0 tratamento com antirretrovirais após ter sido discriminada pelo seu médico. Os resultados de uma pesquisa envolvendo pacientes com HIV/AIDS de uma clínica pública demonstraram que o bom relacionamento médico-paciente tende a promover a maior aderência ao tratamento com antirretrovirais, por outro lado, relacionamentos de baixa qualidade tendem a impedir que isso ocorra ${ }^{25}$.

É importante sabermos de que forma as situações de discriminação na área da saúde são vivenciadas pelos pacientes com HIVIAIDS para que possamos compreendê-las melhor e combatê-las com maior precisão e eficácia. Por meio dos relatos foi possivel perceber que a maioria das situações discriminatórias ocorreu em serviços públicos de saúde, o que pode sugerir que estratégias para o controle das mesmas sejam instituídas primeiramente nesse setor. Tais estratégias deveriam contemplar desde palestras informativas sobre meios de contaminação e potencial de transmissibilidade do HIV em serviços 


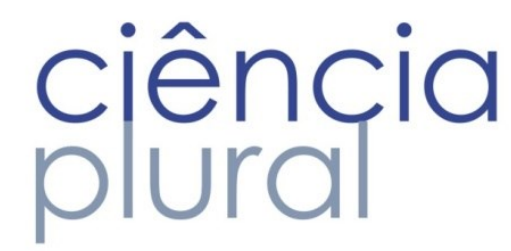

assistenciais de saúde até orientações sobre ética, abordagem e humanização na relação profissional/paciente.

Tendo-se constatado a ocorrência de recusa de atendimento de pessoas com HIVIAIDS em Faculdades da área da saúde, torna-se inegável a necessidade da discussão sobre o tema no ambiente universitário para que medidas oportunas sejam adotadas localmente de acordo com a necessidade e a viabilidade de cada realidade. $O$ que não se pode admitir é que tais situações continuem ocorrendo nesse ambiente norteado por princípios éticos, conhecimento científico e pelo compromisso com a comunidade.

\section{Conclusões}

As situações discriminatórias vivenciadas pelas pessoas com HIVIAIDS ocorreram sob a forma de recusa de tratamento, atendimento diferenciado e adoção de medidas extras de biossegurança, tendo ocorrido inclusive em instituições de ensino superior. Faz-se necessária a adoção de estratégias que visem o controle da ocorrência dessas situações nos serviços de saúde e também em Faculdades de cursos da área da saúde, buscando um atendimento adequado e humanizado. É necessária também a adoção de estratégias junto à sociedade civil que visem diminuir a estigmatização imposta aos portadores do HIV, o que vai colaborar não só com a melhoria na qualidade de vida de pessoas HIV soropositivo como também facilitará a adoção de medidas preventivas pela sociedade, minimizando a falsa ideia da existência de grupos de risco.

\section{Referências}

1. Creel AH, Rimal RN, Mkandawire G, Boose K, Brown JW. Effects of a mass media intervention on HIV-related stigma: 'Radio Diaries' program in Malawi. Health Educ Res. 2011;26:456-65.

2. Soares, GB, Garbin CAS, Rovida TAS, Garbin A Jí. Oral health associated with quality of life of people living with HIVIAIDS in Brazil. Health Qual Life Outcomes. 2014; 12:28.

3. Garbin CAS, Martins RJ, Garbin AJI, Lima DC, Prieto AKC. Percepção de paciente HIV-positivo de um centro de referência em relação a tratamento de saúde. DST - J Bras Doenças Sex Transm. 2009:21:107-10.

4. Ramos S. O papel das ONGs na construção de políticas de saúde: a AIDS, a saúde da mulher e a saúde mental. Ciênc Saúde Coletiva. 2004;9:1067-1078. 


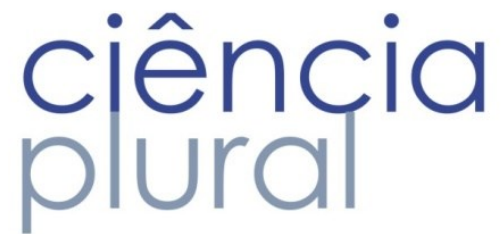

5. Paulilo MAS, Jeolás LS. Aids, drogas, riscos e significados: uma construção sociocultural. Ciênc Saúde Coletiva. 2005;10:175-184.

6. Castro B G, Pereira G, Souza H. AIDS: o que fazer? Cad Saúde Publica. 1986;2: 66-83.

7. Bunting SM. Sources of stigma associated with women with HIV. ANS Adv Nurs Sci. 1996;19:64-73.

8. Khakha DC. Discrimination in health care to patients living with HIV/AIDS. Nurs J India. 2003; 94 (12): 273-5.

9. Merati T, Supriyadi, Yuliana F. The disjunction between policy and practice: HIV discrimination in health care and employment in Indonesia. Aids Care. 2005;17:175-179.

10. Kermode M, Holmes W, Langkham B, Thomas MS, Gifford S. HIV-related knowledge, attitudes \& risk perception amongst nurses, doctors \& other healthcare workers in rural India. Indian $\mathrm{J}$ Med Res. 2005;122:258-264.

11. Jovic-Vranes A, Jankovic S, VukovicD, Vranes B, Miljus D. Risk perception and attitudes towards HIV in Serbian health care workers. Occup Med. 2006;56:275-278.

12. Juan $\mathrm{CW}$, Siebers R, Wu FFS, Wu CJ, Chang YJ, Chao $\mathrm{C}$. The attitudes, concerns, gloving practices and knowledge of nurses in a Taiwanese hospital regarding AIDS and HIV. Int J Nurs Pract. 2004;10:32-38.

13. Massiah E, Roach TC, Jacobs C, St John AM, Inniss V, Walcott J, et al. Stigma, discrimination, and HIVIAIDS knowledge among physicians in Barbados. Rev Panam Salud Publica .2004;16:395-401.

14. Chen WT, Han M, Holzemer WL. Nurses' knowledge, attitudes, and practice related to HIV transmission in northeastern China. AIDS Patient Care STDS 2004;18:417-422.

15. Infante C, Zarco A, Cuadra SM, Morrison K, Caballero M, Bronfman M, et al. El stigma asociado al VIH/SIDS: el caso de los prestadores de servicios de salud en México. Salud Pública Mex .2006;48:141-50. 16. Minayo MCS. 0 desafio do conhecimento: pesquisa qualitativa em saúde. $9^{a}$ ed. São Paulo: Hucitec; 2006.

17. Schuster M A, Collins R, Cunningham WE, Morton SC, Zierler S, Wong M et al. Perceived discrimination in clinical care in a nationally representative sample of HIV-infected adults receiving health care. J Gen Intern Med. 2005;20:807-813.

18. Panebianco S, del Rio C, Baez-Villasenor J, Uribe P, Morales G. Human rights violations and AIDS: two parallel public health epidemics. Int Conf AIDS. 1994;10: 63.

19. Nöstlinger C, Rojas Castro D, Platteau T, Dias S, Le Gall J. HIV-Related discrimination in European health care settings. AIDS Patient Care STDS. 2014 Mar;28(3):155-61.

20. Elford J, Ibrahim F, Bukutu C, Anderson J. HIV-related discrimination reported by people living with HIV in London, UK. AIDS Behav. 2008 Mar;12(2):255-64. 


\section{ciência plural}

21. Pagliari AV, Garbin AS, Garbin AJI. HIV attitudes and practices among professors in a brazilian dental school. J Dent Educ. 2004;68:1278-1283.

22. Giuliani M, Lajolo C, Rezza G, Arici C, Babudieri S, Grima P,et al. Dental care and HIV-infected individuals: are they equally treated? Community Dent Oral Epidemiol. 2005;33:447-453.

23. Soares GB, Garbin CAS, Rovida TAS, Garbin AJÍ. Qualidade de vida de pessoas que vivem com HIVIAIDS assistidas no serviço especializado em Vitória (ES), Brasil. Ciênc Saúde Coletiva. 2015;20(4), $1075-1084$

24. Hadorn DC. The problem of discrimination in health care priority setting. JAMA. 1992;268: 1454-1459.

25. Roberts KJ. Physician-patient relationships, patient satisfaction, and antiretroviral medication adherence among HIV-infected adults attending a public health clinic. AIDS Patient Care STDS. 2002;16:4350 . 